\title{
Uma Proposta para o Desenvolvimento de Aplicações Orientada a Equipes Interdisciplinares
}

\author{
Emanuel F. Coutinho ${ }^{1}$, Leonardo O. Moreira $^{1}$, Gabriel Paillard ${ }^{1}$ \\ ${ }^{1}$ Instituto Universidade Virtual (UFC Virtual) - Fortaleza - CE \\ Universidade Federal do Ceará (UFC) - CE - Brasil \\ \{emanuel, leoomoreira, gabriel\}evirtual.ufc.br
}

\begin{abstract}
Resumo. Em geral, cursos mais técnicos tendem a ter uma grade curricular orientada a produção e tecnologias. Entretanto, devido à globalização e tratamento de fatores técnicos e humanos ao mesmo tempo, adequar essa realidade aos cursos técnicos se torna uma tarefa difícil. Atualmente, a interdisciplinaridade está ganhando espaço, juntando diferentes áreas para um propósito maior. O objetivo deste trabalho é apresentar uma proposta de pesquisa para a integração de equipes com diferentes perfis, focando no desenvolvimento de sistemas diversificados e no desenvolvimento de times interdisciplinares.
\end{abstract}

\section{Introdução e Motivação}

Em geral, disciplinas de cursos de graduação no contexto técnico tendem a ter uma abordagem curricular voltada para produção e tecnologias. Comumente, disciplinas, como Engenharia de Software, possuem uma visão direcionada e específica para o desenvolvimento de software com foco no desenvolvedor tradicional. Disciplinas que alinham teoria e prática são normalmente difíceis de se conduzir devido à necessidade de se tratar fatores técnicos (linguagens de programação, ferramentas, componentes etc) e humanos (comunicação, gestão, disponibilidade etc) ao mesmo tempo [Coutinho et al. 2016]. Aspectos de áreas diferentes das que tradicionalmente desenvolvem sistemas, como Saúde e Humanas, estão cada vez mais utilizando recursos de software em suas atividades e pesquisas, implicando na necessidade de uma relação e integração entre as diversas áreas.

Atualmente a interdisciplinaridade está ganhando espaço e unindo áreas diferentes para um propósito maior. Interdisciplinaridade é uma teoria sistematizada comum a um grupo de disciplinas conexas e definidas no nível hierárquico imediatamente superior, o que introduz a noção de finalidade [Japiassu 1976]. É um sistema de dois níveis e de objetivos múltiplos, com coordenação procedendo de um nível superior. A interdisciplinaridade se caracteriza pela intensidade das trocas entre os especialistas e pelo grau de integração real das disciplinas, no interior de um projeto específico de pesquisa. Assim, uma discussão preliminar tem que ocorrer diante da definição do propósito do projeto.

O objetivo deste trabalho é apresentar uma proposta de pesquisa para a integração de equipes de perfis variados, mas com foco no desenvolvimento de sistemas tradicionais (e.g. web e mobile), com elementos e características não convencionais (e.g. computação física e acessibilidade), promovendo o desenvolvimento de times interdisciplinares.

\section{Proposta de Pesquisa}

A ideia da pesquisa é promover a união mais efetiva de perfis de desenvolvedores tradicionais de sistemas de maneira geral (web, mobile e banco de dados) com desenvolvedores 
com perfil de design gráfico digital, com foco em interfaces humano-computador, usabilidade e acessibilidade. A princípio essa junção seria a meta inicial, mas ao longo do tempo novos perfis variados iriam sendo incorporados, principalmente perfis com características de audiovisual, animação digital e sistemas embarcados. Assim, aos poucos uma interdisciplinaridade de fato poderia estar sendo promovida, onde cada um trabalharia um aspecto da aplicação a ser desenvolvida com foco no atendimento de um objetivo maior.

\section{Metodologia da Pesquisa}

Tem-se a intenção de experimentar a proposta em um curso de graduação com características interdisciplinares. Para isso, selecionou-se o curso de graduação em Sistemas e Mídias Digitais, da Universidade Federal do Ceará, com as seguintes etapas planejadas:

- Seleção de Disciplinas: Diversas disciplinas no curso são compatíveis para a pesquisa, pois existem perfis variados tantos dos docentes quanto dos discentes. Neste momento, é necessário selecionar um conjunto de disciplinas que contenham os elementos iniciais da pesquisa: desenvolvimento de sistemas e design digital.

- Treinamento dos Docentes: Repasse de alguns conceitos de interdisciplinaridade aos docentes, exemplos, e alguns conceitos de áreas diferentes de formação. Assim, todos os docentes teriam um alinhamento mínimo conceitual sobre outras áreas, facilitando a comunicação para melhor gerenciar as atividades.

- Integração de Atividades: A meta é trabalhar aspectos variados e, de certa forma, sair da zona de conforto. Atividades não comuns de cada disciplina (área) devem ser planejadas. Tanto discentes quanto docentes devem interagir entre si para um melhor fluxo da informação, melhorando a condução das atividades (gerenciais e execução).

- Projetos Integradores: Planejar um projeto integrador, com objetivos bem definidos, que contemple características conceituais e técnicas de todas as disciplinas envolvidas/selecionadas. Esse projeto seria gerenciado pelos docentes, que periodicamente alinhariam às necessidades do projeto e produto, com as necessidades dos discentes.

- Execução e Acompanhamento: Basicamente é o acompanhamento das atividades conforme o planejado. Em caso de replanejamento, é interessante o re-alinhamento com todos da equipe, pois para algumas áreas o impacto pode ser maior.

\section{Conclusão}

Esta pesquisa pretende realizar a junção de profissionais de perfis diferentes de formação, como desenvolvedores e designers digitais, em um mesmo projeto de desenvolvimento de aplicações, com características interdisciplinares, para atender um objetivo comum. A ideia é promover uma melhor comunicação, mesmo com perfis variados, preocupando-se com o correto fluxo da informação entre as partes envolvidas. O estudo ainda está em um estágio inicial, mas as possibilidades de se trabalhar de maneira interdisciplinar nas disciplinas do curso selecionado se mostraram promissoras. Estudos preliminares estão ocorrendo, e espera-se que resultados mais concretos estejam disponíveis em breve.

\section{Referências}

Coutinho, E. F., Gomes, G. A. M., e Júnior, A. J. M. L. (2016). Applying design thinking in disciplines of systems development. In 8th Euro American Conference on Telematics and Information Systems (EATIS2016).

Japiassu, H. (1976). Interdisciplinaridade e Patologia do Saber. IMAGO Editora LTDA, 1 edition. 